\title{
Evaluation methods for evacuation planning
}

\author{
F. Russo \& C. Rindone \\ Department of Computer Science, Mathematics, Electronics and \\ Transportation, Mediterranea University of Reggio Calabria, Italy
}

\begin{abstract}
In this paper the main evaluation methods to support evacuation planning in urban system are presented.

In most cases, evaluation methods require knowledge of functions for relating variables that represent elements to evaluate. Nevertheless in real applications, functions for modelling evacuation are not always available. In these cases, sometimes it is necessary to use a method without the requirement for an explicit a priori determination of these functions.

In this paper we propose two classes of methods to compare an evacuation plan, based on efficiency measures. An evacuation is represented by means of a virtual production process.

An efficiency criterion is adopted to compare different evacuation process. Parametric and non parametric methods to estimate efficiency are compared. Input and output variables to represent an evacuation process are analysed.

Keywords: evacuation plan, evaluation methods, efficiency, parametric and non parametric methods.
\end{abstract}

\section{Introduction}

An evacuation plan allows one to analyse and reduce risk and its relative exposure component [1].

Evacuation planning has been developed for different systems (single building, land system, transportation system and industrial system) [2]. In recent years, modelling tools, Decision Support Systems (DSS) and real experimentations (or exercises) to simulate and to implement an evacuation have been developed. These tools assist decision makers in preparing evacuation plans [3]. 
A generic evacuation plan is characterised by means of different elements (resources, strategies, objectives ...). Single elements can be analysed by means of specific indicators. Based on these elements and relative indicators, different evacuation plans can be compared.

In literature there are several evaluation methods for planning. Methods for ex ante analysis of a transport plan are based on simulation models to represent elements of the plan. Results of simulations can be tested and validated after implementation of the plan adopting monitoring procedures (ex post evaluations) [4].

The evacuation planning requires two different classes of analysis: estimation of evacuation planning indicators that consist into reproduction of a transport system in emergency condition to obtain the representative variables of functioning as: link flows, link times, global times,...; evaluation of evacuation planning that consist into comparisons among different evacuation plans in the framework of risk reduction as formally defined in literature [5].

Estimation of evacuation planning is complex because it is not ever tested in the reality. Some real factors, that could influence evacuation procedures, are not ever modelled because the functions for modelling these factors are only recently studied and developed. For instance, in the SICURO research project, developed by LAST (Laboratory for Transport Systems Analysis), models to estimate urban evacuation planning are proposed [1]. For these reasons two different approaches to estimate an evacuation plan can be adopted:

- a first approach is to apply simulation models of mobility in emergency condition (simulation approach);

- a second approach is to realise real experimentations (or exercises) of an evacuation, finalised to reproduce in the reality mobility in evacuation conditions (exercise approach).

Each approach allows one to obtain data (simulated or observed) about evacuation process.

To follow the first approach a set of models can be applied to simulate different mobility choice dimensions in evacuation. Generally, traditional four stage approach is adopted to simulate a transport system in ordinary conditions and this approach is directly extended to simulate a transport system in evacuation condition extending the travel conditions and choices to the evacuation conditions and choices: generation choice, related to need to evacuate; distribution choice, related to destinations that could be reached to evacuate; modal choice, related to transport modes that could be used to evacuate; path choice, related to paths that could be choose to evacuate.

To simulate an urban system in emergency conditions this set of simulation model cannot be directly applied for several reasons connected to multiplicity of decision-makers, to specific characteristics of choice set, to statistical and probabilistic aspects $[5,6]$. In the SICURO research project a set of models to simulate an urban system in evacuation conditions is proposed: demand models and SP evolutions [6-8]; simulation models of transport supply to represent performances of infrastructure and services in evacuation condition and supplydemand interaction for users, to estimate vehicle evacuation times to reach 
refuge areas [9-11]; design of path choice models for emergency vehicles, to estimate times to evacuate weak users and pupils [12-14]; simulation models of the refuge area for users, to estimate access times [15].

To follow the second approach, in literature, a set of methods to organise and to realise real experimentations are available. In Italy a method to organise evacuation procedures is proposed from National Civil Protection [16]. In the SICURO project real experimentations are planned and implemented to monitor two evacuation tests of an urban area. In US, seven types of real experimentations of an evacuation (exercises) are identified, whit increasing levels of complexity: discussion based that includes seminars, workshops, tabletops, games; operations based that include drills, functional exercises, and full-scale exercises [17].

Results of these experimentations can be measured with a monitoring system. These measures allows to realise a comparisons with results obtained from application of simulation models. Exercises performed for transport system in emergency conditions are different respect to ordinary condition. In emergency condition a set of real phenomenon, that could influence user behaviours such as panic situations, human errors and so on, cannot be reproduced.

Traditional evaluation methods, as cost-benefit analysis, have some limitations for evacuation planning. A set of factors, that could influence decision-makers, could not be considered.

In this paper, to overcome these limitations, several evaluation methods, generally applied in other context, are proposed. The proposed methods are based on assumption that an evacuation process is represented how a virtual production process. The process is fed from a set of inputs that are combined to obtain a set of outputs. Input and output sets can be represented by means of specific variables. In the following this process is named evacuation production process. Connections among input and output of the process can be represented by means of production functions. Efficiency is adopted how criterion to evaluate the process.

In the economics literature, efficiency is sometimes considered a characteristic of production process that is a set of activities by which factors of production (or inputs) are combined to obtain one or more products (or outputs). A production process can be represented by means of a production function that describes the technical relationship between the inputs and output of the process [18]. A frontier production function is an extension of a production function and represents the maximum output attainable given a set of inputs [19].

Adopting Farrell's definition [20], efficiency represents success in producing as large as possible an output from a given set of inputs. The European Commission defines efficiency as the best relationship between resources employed and results achieved [21]. In general, efficiency measures the capacity of a Decision Making Unit (DMU) to create a production process that combines production factors (inputs) to obtain products (outputs). In engineering, efficiency of a production process is achieved when it is possible to obtain the maximum amount of output that is physically achievable with current technology, given a fixed amount of inputs 0 . 


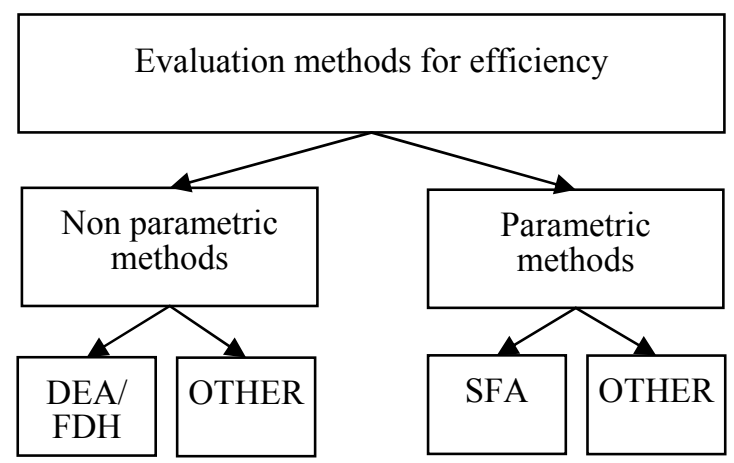

Figure 1: Classification of evaluation methods for efficiency.

A possible classification of methods to measure efficiency is based on knowledge, or not, of the production function (Figure 1):

- non-parametric methods, based on the assumption that the production function of fully efficient firms is not known; possible methods are Data Envelopment Analysis (DEA) [22] and Free Disposal Hull (FDH) [23];

- parametric methods, based on the assumption that the production function of fully efficient firms is known [18]; a possible method is Stochastic Frontier Analysis (SFA) [24, 25].

In section 2, evaluation methods for evacuation planning are proposed. These methods are based on non-parametric and parametric methods to evaluate efficiency of a production process. Input and output variables to represent an evacuation process are analysed in section 3 .

\section{Evaluation methods for evacuation planning}

Evaluation methods allow one to compare the effects of different plans in respect to one or more criteria. In this paper efficiency criterion is considered. In literature several methods to measure efficiency are available (section 2.1). In this paper non parametric methods (section 2.2) and parametric methods (section 2.3) to measure efficiency are considered.

\subsection{Efficiency for evacuation planning}

In the following, an evacuation is represented by means of an evacuation (production) process, in the following shortly evacuation process. The process is fed by a set of one or more inputs that provide a set of one or more outputs. Performances of this process are measured in terms of efficiency that depends on hypothesis about combinations of inputs and outputs.

Considering a set of $j=1, \ldots, n$ evacuation process, that in general could include a subset of evacuation output obtained by simulation models and a subset 
of evacuation output obtained by real experimentations, each element of the set can be represented by:

- a set of inputs that fed the process; this set is formally represented from a vector of input variables relative to $\mathrm{j}^{\text {th }}$ process, whit $1 \times r$ dimension, where $r$ is the number of inputs considered,

$$
\mathbf{i}_{\mathrm{j}}:\left(\mathrm{i}_{\mathrm{i}}, \mathrm{i}_{2}, \ldots, \mathrm{i}_{\mathrm{r}}\right)^{\mathbf{T}} \quad \mathrm{j}=1, \ldots, \mathrm{n}
$$

- a set of outputs resulting from the process; this set is formally represented from a vector of output variables relative to $\mathrm{j}^{\text {th }}$ process, whit $1 \times s$ dimension, where $r$ is the number of inputs considered,

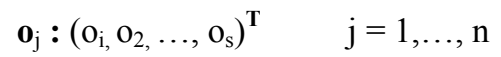

A common measure of efficiency is represented from the ratio between aggregate output and aggregate inputs.

\subsection{Non parametric methods}

Non parametric methods are based on comparison among different evacuation process, with non-requirement of an explicit a priori determination of relationships between output and inputs. The comparison is finalised to obtain a frontier that constitute a term of reference for the evacuation process set. Elements of this set are assumed belonging to a production possibility set [26].

Considering an homogeneous set of $j=1, \ldots, n$ evacuation process, where each element is represented by a set of inputs and a set of outputs $\left(\mathbf{i}_{\mathrm{j}}, \mathbf{o}_{\mathrm{j}}\right)$, non parametric methods allows to obtain a frontier of production possibility set. Adopting notation introduced in section 2.1, a generic efficiency function expressed by non parametric function has the following form:

$$
\mathrm{f}_{\mathrm{np}}=\mathrm{g}_{\mathrm{np}}\left(\mathbf{i}_{\mathrm{j}}, \mathbf{o}_{\mathrm{j}}\right)
$$

where:

$$
\begin{array}{ll}
\mathrm{f}_{\mathrm{np}} & \text { is the generic efficiency function; } \\
\mathrm{g}_{\mathrm{np}} & \text { is the specification of non parametric function. }
\end{array}
$$

Efficient processes must belong to the frontier. The distance from the frontier is a measure of inefficiency of the process.

\subsection{Parametric methods}

Parametric methods are based on knowledge of production function to represent relationship among input and output of an evacuation production process. Production function allows estimating efficiency.

Considering a set of $j=1, \ldots, n$ evacuation production process, where each element is represented by a set of inputs and a set of output $\left(\mathbf{i}_{\mathrm{j}}, \mathbf{o}_{\mathrm{j}}\right)$, parametric 
methods allows to obtain a production function that relates input and output variables representative of each process. Adopting notation introduced in section 2.1, a generic efficiency function expressed by a production function has the following form:

$$
\mathrm{f}_{\mathrm{p}}=\mathrm{g}_{\mathrm{p}}\left(\mathbf{i}_{\mathrm{j}}, \mathbf{o}_{\mathrm{j}}\right)
$$

where:

$$
\begin{array}{ll}
\mathrm{f}_{\mathrm{p}} & \text { is the generic efficiency function; } \\
\mathrm{g}_{\mathrm{p}} & \text { is the specification of production function. }
\end{array}
$$

\section{Variables}

Elements of evacuation process can be studied adopting a set of quantitative variables. In this section, following the literature definitions [26], these variables are classified on input variables (section 3.1) and output variables (section 3.2).

\subsection{Input}

Given socioeconomic characteristics of the area of interest by evacuation plan (population, land characteristics...), inputs comprehend one class of variables: the needed resources to realise interventions (activities) for the implementation of an evacuation plan. It is necessary to define temporal and financial specification of resources.

Classification of activities is based on elements of transport system that can be modified following planner's decisions:

- material infrastructures, that comprehend physical characteristics of transport system elements (e.g. realisation of refuge's area);

- immaterial infrastructures, that comprehend technologic characteristics of transport system elements other than the classical one relative to training and research (e.g. Intelligent Transport System);

- $\quad$ equipment elements, that comprehend operative means to realise transport services (e.g. emergency vehicles);

- managerial elements, that comprehend organisational characteristics of transport system, in terms of transport services (e.g. emergency services);

- normative elements, which comprehend rules to govern the planning procedure (e.g. decisions about evacuation procedures).

Each class of activities requires a different time for realisation. Generally, temporal development of activities, to improve transport system, is assumed according to planning time dimensions:

- at short time, operative scale, activities concern modification on managerial and normative elements of transport system; these activities have influence on path and mode choice component of mobility; to implement this class of activities, a low quantity of resources is needed; 
- at medium time, tactical scale, activities concern modification on equipment, and immaterial infrastructures of transport system, other than on managerial and normative elements; these activities have influence on distribution, other than path and mode choice component of mobility; to implement this class of activities, a medium quantity of resources is needed;

- at long time, strategic scale, activities concern a modification on material and immaterial infrastructures of transport system; these interventions have influence on emission, distribution, mode and path choice component of mobility and socio-economic characteristics (population and employment); to implement this class of activities, a high quantity of resources is needed.

\subsection{Output}

Output variables comprehend results of planner's decisions to improve evacuation process.

A possible classification of output variables is based on the typology of results obtained from planner's decisions:

- direct results, that measure the quantity of simulations and/or real exercises produced; possible measures for this class of input variables can be, number of simulations or exercises for city's part,

- number of simulations or exercises for cities,

- number of emergency vehicles used during an evacuation,

- number of emergency services supplied during an evacuation,

- intermediate results, that measure the quality of evacuation plans produced for instance in terms of evacuation times estimated by simulation models or measured by monitoring; possible measure for this class of output variables can be,

- evacuation times of a city's part,

- evacuation times of a city;

- link flows of urban road network during an evacuation;

- link times of urban road network during an evacuation;

- total travel times of urban road network during an evacuation.

\section{Preliminary (final) indications}

Parametric methods can be applied when the structure of the relationships between input and output is known. For evacuation planning only some prototype of these relationships are available.

Nevertheless, in most cases information to reconstruct efficiency functions are unknown. For this reason, application of non parametric methods could be useful. Construction of efficiency function not requires an explicit determination of relationships between output and inputs. Non parametric methods allow one to obtain immediate results. On the other hand, non parametric methods adopt several simplifications to represent evacuation process. Moreover, it is important to pay attention at inputs and outputs choice because some of these variables can be mutually correlated. 


\section{References}

[1] Russo F. \& Vitetta A., Safety of users in road evacuation: General methodology and main results. Proc. of Urban Transport XIII, Urban Transport and the Environment in the 21st century, Brebbia C. A. (ed.), WIT Press, Southampton, pp. 763-772, 2007.

[2] Russo F. \& Rindone C., Safety of users in road evacuation: planning internal processes and guidelines. Proc. of Urban Transport XIII, Urban Transport and the Environment in the 21st century, Brebbia C. A. (ed.), WIT Press, Southampton, pp. 825-834, 2007.

[3] Russo F. \& Rindone C., Safety of users in road evacuation: Modelling and DSS for LFA in the planning process. Proc. of Sustainable Development and Planning IV, vol.1, Brebbia C. A. (ed.), WIT Press, Southampton, pp. 453-464, 2009.

[4] Russo F. \& Rindone C., Safety of users in road evacuation: the logical framework approach in evacuation planning. Proc. of Urban Transport $X I V$, Urban Transport and the Environment in the 21st century, Brebbia C. A. (ed.), WIT Press, Southampton, pp. 751-760, 2008.

[5] Russo F. \& Vitetta A., Risk evaluation in a transportation system. International Journal of Sustainable Development and Planning, 1 (2), pp. 170-191, 2006.

[6] Russo F. \& Chilà G., Safety of users in road evacuation: demand models. Proc. of Urban Transport XIII, Urban Transport and the Environment in the 21st century, Brebbia C. A. (ed.), WIT Press, Southampton, pp. 773$782,2007$.

[7] Russo F. \& Chilà G., Safety of users in road evacuation: RP vs. SP surveys in demand analysis. Proc. of Urban Transport XIV, Urban Transport and the Environment in the 21 st century, Brebbia C. A. (ed.), WIT Press, Southampton, pp. 703-713, 2008.

[8] Russo F. \& Chilà G., Safety of users in road evacuation: Modelling and DSS for demand. Proc. of Sustainable Development and Planning IV, vol.1, Brebbia C. A. (ed.), WIT Press, Southampton, pp. 465-474, 2009.

[9] Vitetta A., Musolino G. \& Marcianò F.A., Safety of users in road evacuation: Supply and demand-supply interaction models for users. Proc. of Urban Transport XIII, Urban Transport and the Environment in the 21st century, Brebbia C. A. (ed.), WIT Press, Southampton, pp. 783-792, 2007.

[10] Vitetta A., Musolino G. \& Marcianò F. A., Safety of users in road evacuation: calibration of cost functions and simulation. Proc. of Urban Transport XIV, Urban Transport and the Environment in the 21st century, Brebbia C. A. (ed.), WIT Press, Southampton, pp. 715-725, 2008.

[11] Vitetta A., Musolino G. \& Marcianò F.A., Safety of users in road evacuation: Modelling and DSS for transport supply and supply-demand interaction. Proc. of Sustainable Development and Planning IV, vol.1, Brebbia C. A. (ed.), WIT Press, Southampton, pp. 475-484, 2009.

[12] Vitetta A., Quattrone A. \& Polimeni A., Safety of users in road evacuation: design of path choice models for emergency vehicles. Proc. of Urban 
Transport XIII, Urban Transport and the Environment in the 21st century, Brebbia C. A. (ed.), WIT Press, Southampton, pp. 803-812, 2007.

[13] Vitetta A., Quattrone A. \& Polimeni A., Safety of users in road evacuation: algorithms for path design of emergency vehicles, Proc. of Urban Transport XIV, Urban Transport and the Environment in the 21st century, Brebbia C. A. (ed.), WIT Press, Southampton, pp. 727-737, 2008.

[14] Vitetta A., Quattrone A. \& Polimeni A., Safety of users in road evacuation: Modelling and DSS for paths design of emergency vehicles. Proc. of Sustainable Development and Planning IV, vol.1, Brebbia C. A. (ed.), WIT Press, Southampton, pp. 485-495, 2009.

[15] Vitetta A. \& Assumma V., Safety of users in road evacuation: Simulation of Refuge's Area for Users. Proc. of Urban Transport XIII, Urban Transport and the Environment in the 21st century, Brebbia C. A. (ed.), WIT Press, Southampton, pp. 793-802, 2007.

[16] Italian Department of Civil Protection, "Pianificazione e gestione dell'emergenza - Il metodo Augustus" http://www.protezionecivile.it/ (February 2009), 1997.

[17] Homeland Security Exercise and Evaluation Program (HSEEP), https://hseep.dhs.gov/pages/1001_HSEEP7.aspx (February 2009), 2009

[18] Coelli T., Rao D. S. P. \& Battese G. E., An Introduction to Efficiency and Productivity Analysis, Kluwer Academic Publishers, 1998.

[19] Pesaran M. H. \& Schmidt P., Handbook of Applied Econometrics Volume II: Microeconomics. Blackwell Publishing. Blackwell Reference Online, 1999.

[20] Farrell M. J., The measurement of productive efficiency. Journal of the Royal Statistical Society A, 120, pp. 253-281, 1957.

[21] European Commission, Evaluation of Cohesion Policy, http://ec.europa.eu/regional_policy/sources/docgener/evaluation/ evaluation en.htm, (February 2010), 2004

Diewert E., W. \& Lawrence D. "Measuring New Zealand's Productivity", Treasury Working Paper 99/5, http://www.treasury.govt.nz/workingpapers/ 99-5.htm, (February 2010), 1999.

[22] Charnes A., Cooper W.W. \& Rhodes E., Measuring the efficiency of decision making units. European Journal of Operational Research, 2, pp. 429-444, 1978.

[23] Deprins D., Simar L. \& Tulkens H., Measuring labour-efficiency in post offices. Marchand M., Pestieau P., Tulkens H. (ed.), The Performance of Public Enterprises. Elsevier Science Publishers, Amsterdam, pp. 243-267, 1984.

[24] Aigner D., Lovell K. \& Schmidt P., Formulation and estimation of stochastic frontier models. Journal of Econometrics 6 (1), pp 21-37, 1977.

[25] Meeusen W. \& van de Broeck J., Efficiency estimation from Cobb-Douglas production function with composed error, International Economic Review, 18 , pp. 435-444, 1977

[26] Cooper W.W., Seiford L.M. \& Tone K., Data Envelopment Analysis. Kluwer Academic Publisher, Boston, USA, 2000. 